\title{
Environmental Application of Photochemical Method for the Degradation of Rhodamine B Dye in Aqueous Media Using Modified Titania
}

\author{
P. BUELA NESA KUMARI* and G. ALLEN GNANA RAJ
}

Department of Chemistry and Research Centre, Scott Christian College, (Autonomous)

Nagercoil, Tamilnadu, India

bueladavid@gmail.com

Received 17 December 2015 / Accepted 11 January 2016

\begin{abstract}
The development of semiconductor photocatalysis for a wide range of environmental and energy applications. One of the most significant and commercial advances has been the development of visible light active $\mathrm{TiO}_{2}$ photocatalytic materials. In the present study, a visible light active $\mathrm{TiO}_{2}$ photocatalyst was prepared through Nitrogen doping by using Ammonia as Nitrogen source. Preparation was performed by a sol-gel method at various temperatures such as $400{ }^{\circ} \mathrm{C}, 600{ }^{\circ} \mathrm{C}$ and $800{ }^{\circ} \mathrm{C}$. The resulting photocatalyst was characterized by XRD, SEM, EDAX. The decrease in concentration of rhodamine B was monitored by UV-Visible spectroscopy. The characterizations found that the photocatalyst possessed a high surface area and a crystalline size is about-19 nm, $28 \mathrm{~nm}$ and $52 \mathrm{~nm}$ respectively. On the degradation of rhodamine $B$ in water under visible light irradiation $[\lambda=554 \mathrm{~nm}]$. The photocatalytic activity increased with decrease in concentration of catalyst and increase in light intensity.
\end{abstract}

Keywords: Photocatalyst, Titanium dioxide, Nitrogen doping, Rhodamine B, Visible light

\section{Introduction}

Foreign substances either from natural or anthropogenic sources, contaminated with water supplies, may be harmful to life because of their toxicity, reduction of normal oxygen level to water, aesthetically unsuitable and spread epidemic diseases. About 1-20\% of the total world production of dyes is lost during the dyeing process and is released in the textile effluents ${ }^{1}$. The release of those coloured wastewaters in the environment is a considerable source of non-aesthetic pollution and eutrophication and can originate dangerous byproducts through oxidation, hydrolysis or other chemical reactions taking place in the waste water phase. It must be noted that dyes can present toxic effects and reduce light penetration in contaminated waters ${ }^{2}$.

Traditional physical methods such as ultrafiltration, reverse osmosis, coagulation by chemical agents, ion-exchange methods, adsorption of activated carbon or charcoal have been used for the removal of dye pollutants. These methods only succeed in transferring organic compounds from water to another phase, thus creating secondary pollution. 
The application of titanium dioxide as heterogeneous photocatalyst is altering considerable attention for water and air purification and remediation ${ }^{3-7}$. Because of its large band gap of $3.2 \mathrm{eV}$ it can be activated only under UV light irradiation of wavelength $<387 \mathrm{~nm}$. However, UV light constitutes only a small fraction about $3-5 \%$ of the solar spectrum, it will have a positive effect for improving the photocatalytic efficiency of $\mathrm{TiO}_{2}$ by shifting its optical response to the visible range. So scientists are exploring methods to modify titanium dioxide to absorb visible light. Most of these investigations had been made to convert the $\mathrm{TiO}_{2}$ absorption from the ultraviolet to the visible region to dope $\mathrm{TiO}_{2}$ with transition metals such ${ }^{8-13}$ as $\mathrm{Cr}, \mathrm{Fe}, \mathrm{Mn}, \mathrm{V}$ etc. However, the photocatalytic activity of transition metals doping is poor because of their thermal instability ${ }^{8}$. Recently, doping $\mathrm{TiO}_{2}$ with nonmetal atoms has received much attention. For example, doping of nitrogen ${ }^{14-19}$, carbon ${ }^{20-25}$, sulphur ${ }^{26-28}$ and iodine ${ }^{29}$ in $\mathrm{TiO}_{2}$ can lower its bandgap and shift its optical response to the visible region and also completely mineralize the target pollutants ${ }^{30}$.

In a semiconductor with a large bandgap, electrons in the valence band cannot jump up to the conduction band. However if energy is applied externally, electrons in the valence band can rise to the conduction band. Consequently as many electron holes as the number of excited electrons are created in the valence band. This is equivalent to the movement of electrons from the bonding orbital to the antibonding orbital. In other words, the photoexcited state of a semiconductor is generally unstable and can easily break down. Titanium oxide on the otherhand, remains stable even when it is photoexcited. This is one of the reason that $\mathrm{TiO}_{2}$ makes an excellent photocatalyst.

Rhodamine B is used as model organic dye, as it is most important Xanthene dye and dye pollutants from the textile industry are an important factor in environmental pollution and its degradation mechanism had been studied quite well ${ }^{30-32}$. The photodegradation of rhodamine B in aqueous solution was investigated by UV-Vis spectroscopy.

\section{Experimental}

Various methods are available for the preparation of $\mathrm{TiO}_{2}$-based photocatalysts, such as electrochemical $^{33-38}$, thin films and spin coating ${ }^{39-41}$ precipitation $^{42-46}$, hydrothermal and solvothermal ${ }^{47-52}$, solvochemical and chemical vapour decomposition ${ }^{53-55}$, Although, the benefits derived from preparing $\mathrm{N}-\mathrm{TiO}_{2}$ (NT) by sol-gel method which include synthesis of nanosized crystallized powder of high purity at relatively low temperature, possibility of stoichiometry controlling process, preparation of composite materials, and production of homogeneous materials have driven many researchers to the use of the method in preparing $\mathrm{TiO}_{2}$-based photocatalysts.

Nitrogen doped $\mathrm{TiO}_{2}$ photo catalyst was prepared by sol-gel method using TTIP (titanium tetra isopropoxide) as the precursor of titanium and ammonia water as the source of nitrogen. $12.00 \mathrm{~g}$ of TTIP liquid was mixed with $5 \mathrm{~cm}^{3}$ of absolute ethanol unit, the homogeneous solution was given. Ammonia water is added drop by drop into TTIP under constant stirring, white precipitate was given immediately. Solution with white precipitate was stirred $30 \mathrm{~min}$. and stand $18 \mathrm{~h}$ for aging. After aging white solid was filtered and calcined at $400{ }^{\circ} \mathrm{C}, 600^{\circ} \mathrm{C}$ and $800{ }^{\circ} \mathrm{C}$.

\section{Phocatalytic study}

$0.1 \mathrm{~g}$ of Photocatalyst was suspended in $100 \mathrm{~mL}$ aqueous RB-base dye solution in a $250 \mathrm{~mL}$ beaker. The suspension was stirred for 30 minutes in dark and irradiated under visible light. Samples were taken each 30 minutes, centrifuged and analysed for the degradation of Rhodamine B dye using UV-Visible spectrophotometer (Figure 1a \& 1b). Rhodamine B dye has the maximum absorbance at $554 \mathrm{~nm}$.

Absorbance of rhodamine B against time is recorded with same amount of catalyst with three different calcination temperatures is shown in the Figure 2(a-c). Absorbance is maximum 
using $0.2 \mathrm{~g}$ nitrogen doped $\mathrm{TiO}_{2}$ at $600^{\circ} \mathrm{C}$ and above a mixture of anatase and rutile phase of the sample were formed and hence absorbance somewhat decreases. The photocatalytic percent degradation of rhodamine B against time shown in Figure 3. Results show that all the modified catalysts give a linear relationship with time i.e., up to 120 minutes, after 30 to 35 minutes $0.2 \mathrm{~g}$ NT 600 has better photocatalytic degradation than that of $0.2 \mathrm{~g}$ NT 400 and $0.2 \mathrm{NT} 800$. This indicates that the photocatalytic activity of the prepared photocatalyst reached maximum at $600^{\circ} \mathrm{C}$. Further increase in the calcination temperature from 600 to $800^{\circ} \mathrm{C}$ resulted in lower photocatalytic activity of the prepared photocatalyst. The reason given for this is that the increase in calcination temperature beyond $600{ }^{\circ} \mathrm{C}$ can promote the transformation of anatase to a mixture of anatase and rutile phase, which has little photocatalytic activity.
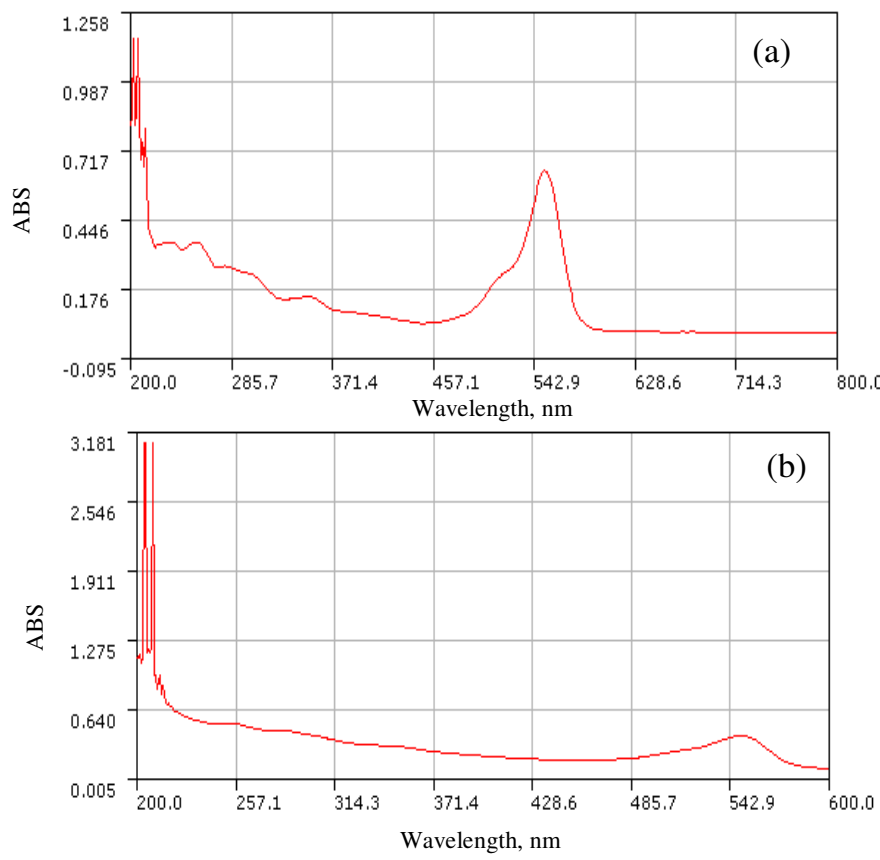

Figure 1. (a) UV of RB Dye (b) UV of RB dye degraded in the presence of $\mathrm{NTiO}_{2}$

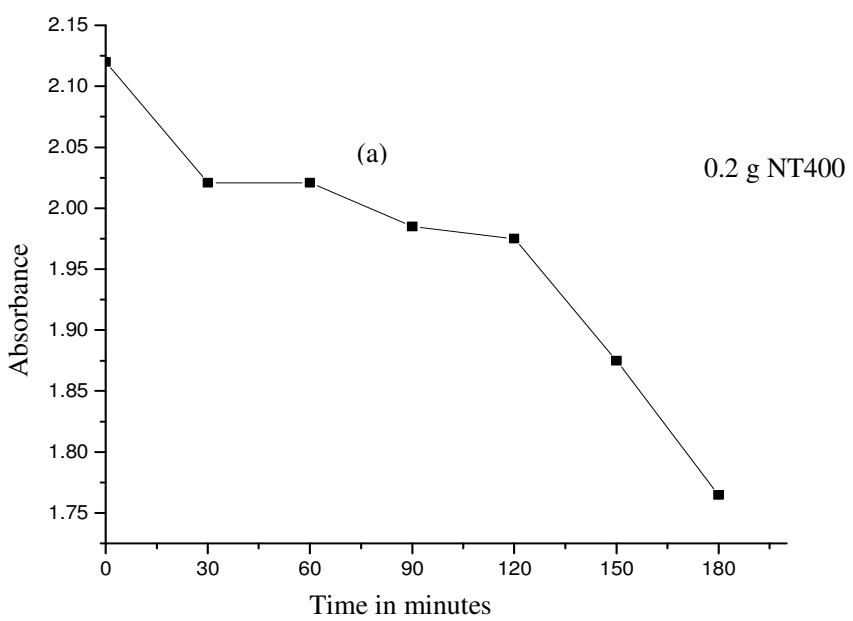



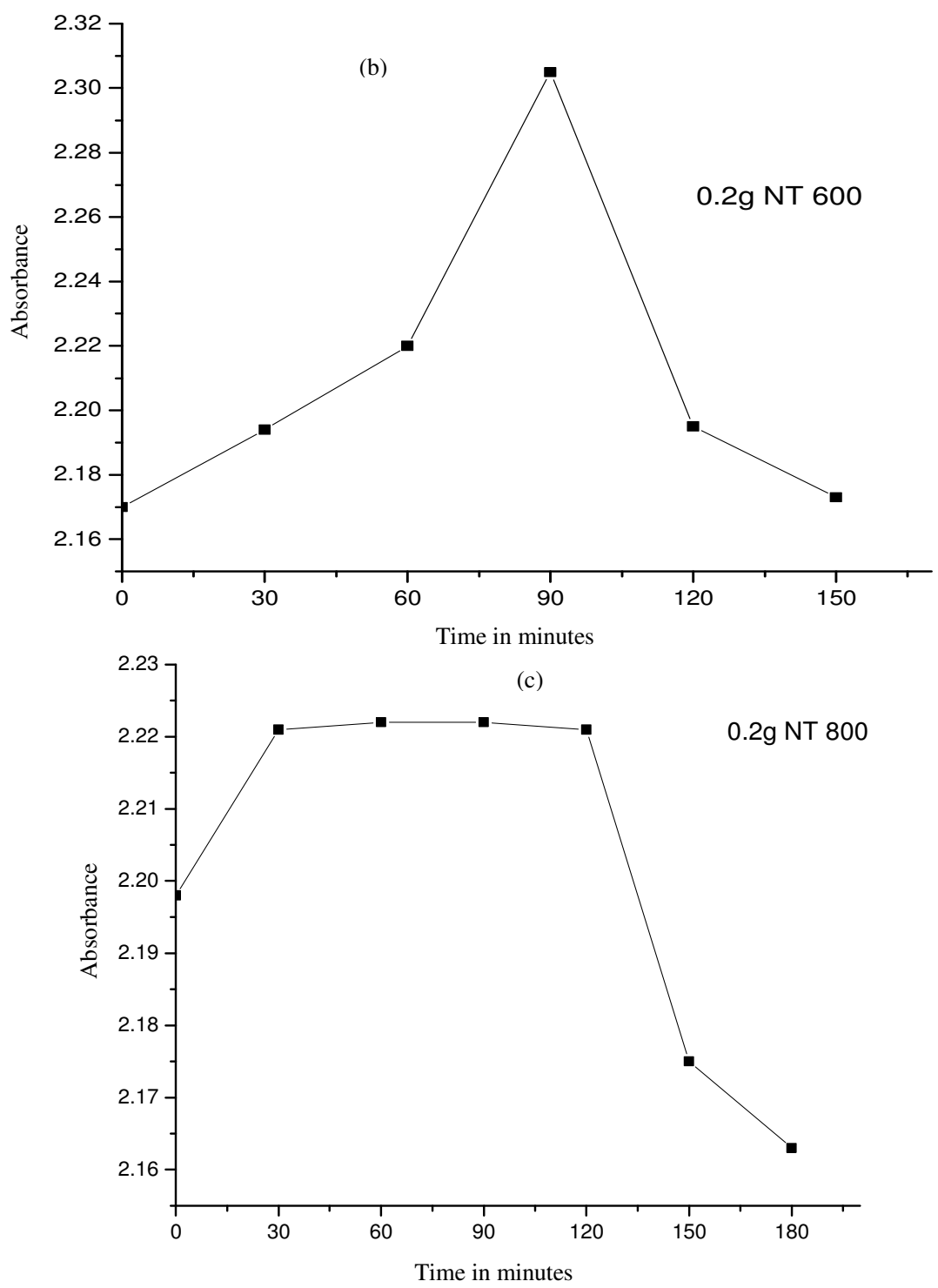

Figure 2. (a) 0.2 g NT 600 (b) 0.2 g NT 400 (c) 0.2 g NT 800

\section{Results and Discussion}

\section{SEM analysis}

The following Figure 4 shows surface morphology of microparticles with high-resolution images of the sample. The as-prepared $\mathrm{N}-\mathrm{TiO}_{2}$ has the small particle size and a good dispersion. A good dispersion of small particles could provide more activated sites for the reactants than the aggregated particles. $\mathrm{TiO}_{2}$ doped with nitrogen gave more porous structure this may be attributed to prevention of $\mathrm{TiO}_{2}$ agglomeration. 


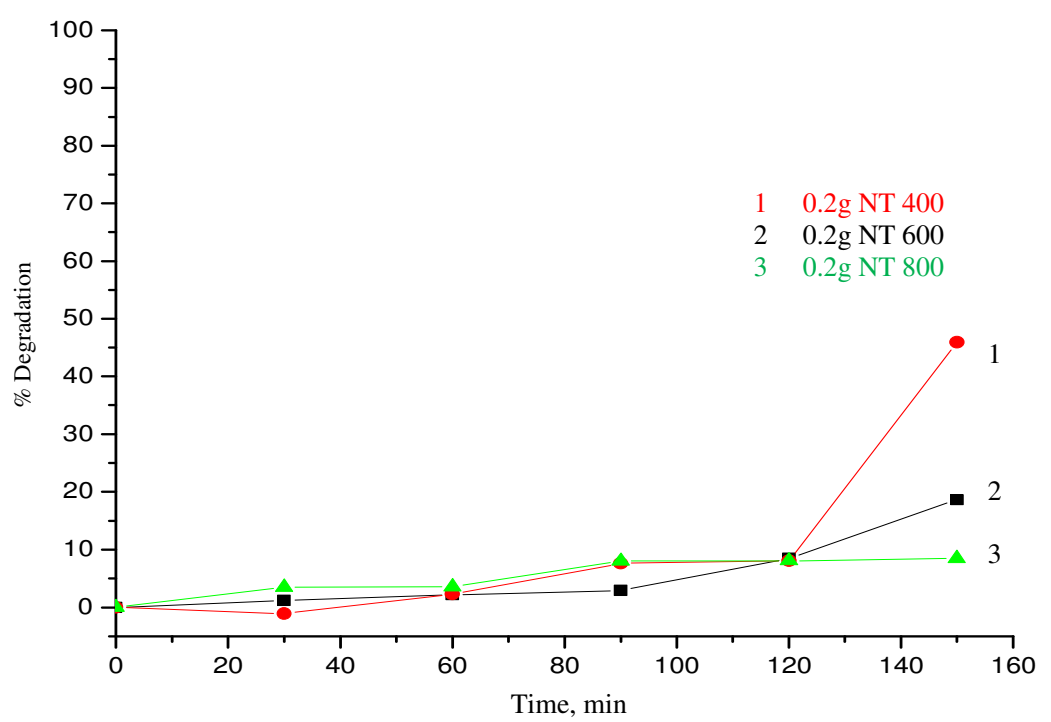

Figure 3. \% Degradation of NT 400, NT 600, NT 800

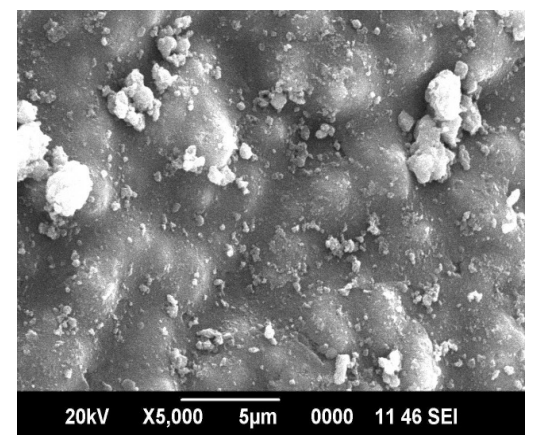

(a)

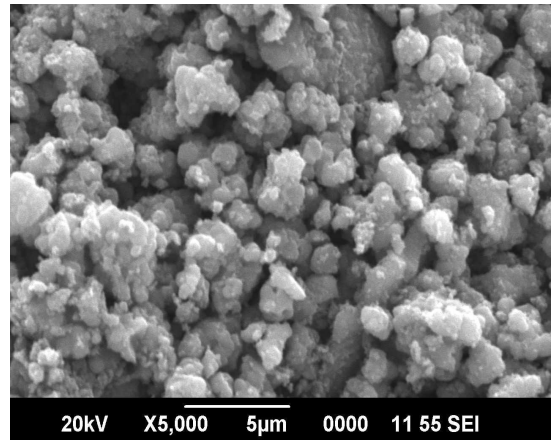

(b)

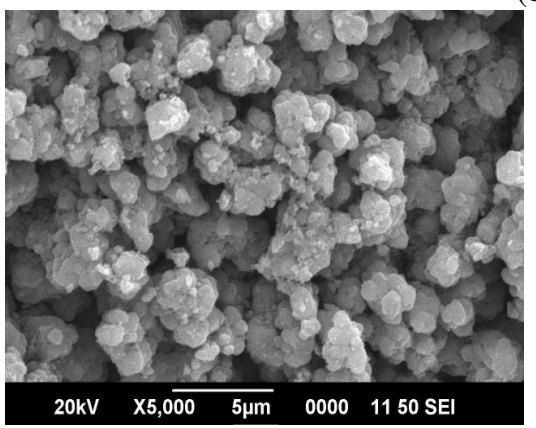

(c)

Fiigure 4. SEM of (a) NT 400 at $5 \mu \mathrm{m}$ (b) NT 600 at $5 \mu \mathrm{m}$ (c) NT 800 at $5 \mu \mathrm{m}$ XRD analysis

XRD was used to find the crystallographic structure of the inorganic component of the photocatalyst. Figure 5 shows the x-ray diffraction patterns of $N$-doped $\mathrm{TiO}_{2}$ prepared with 
different calcinations temperature. All the as-prepared $\mathrm{N}-\mathrm{TiO}_{2}$ materials have single phase, crystalline, anatase $\mathrm{TiO}_{2}$ (JCPDS no. 89-4921) except NT 800 sample, which is poorly crystalline anatase together with a small amount of rutile $\mathrm{N}-\mathrm{TiO}_{2}$. No new diffraction peaks are observed in the $\mathrm{N}$ containing phase.

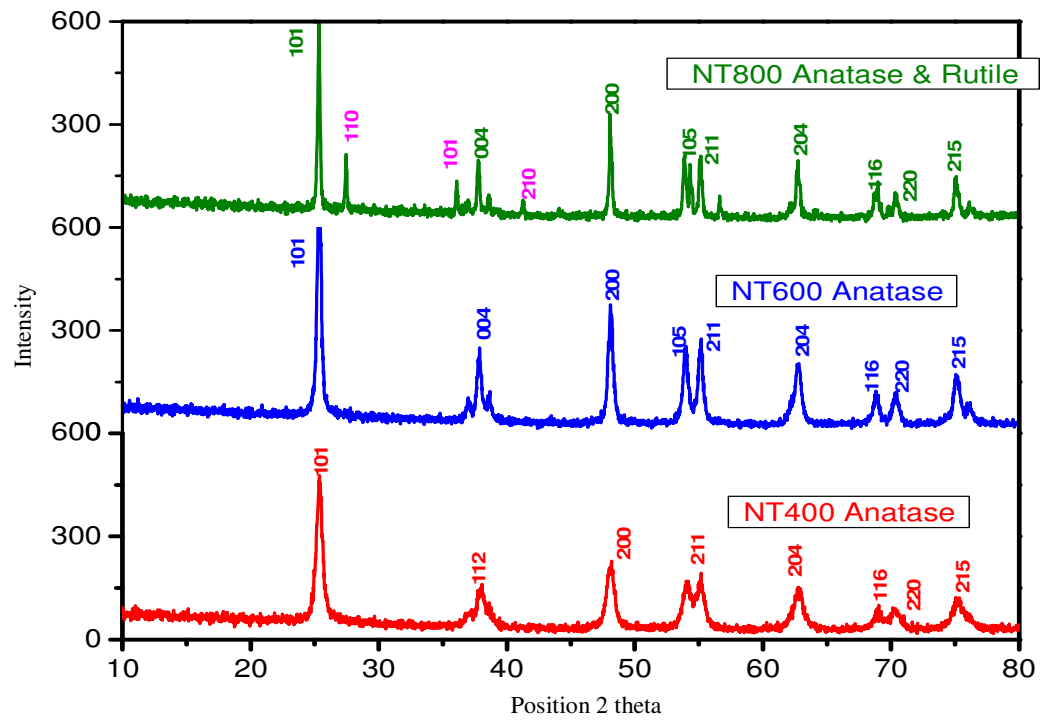

Figure 5. XRD patterns of $\mathrm{N}$-doped $\mathrm{TiO}_{2}$ with calcination temperatues

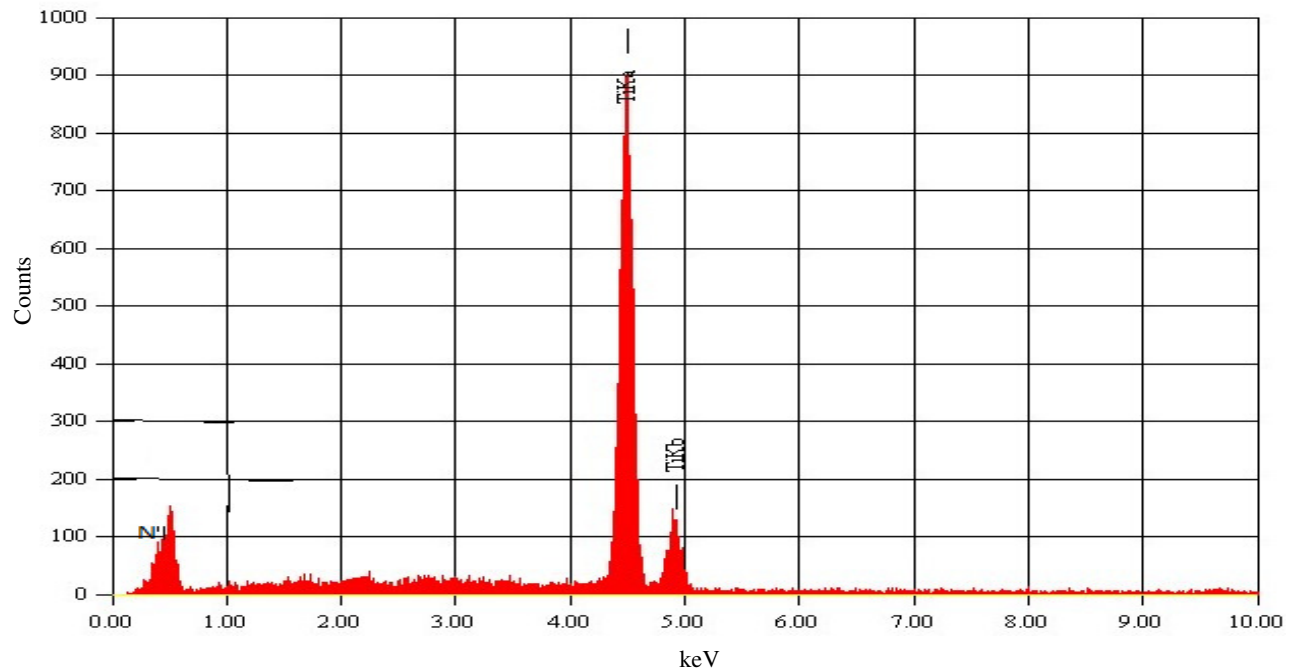

Figure 6. $\mathrm{EDAX}$ of $\mathrm{NTiO}_{2}$

Table 1 lists the crystal size of $\mathrm{N}$-doped $\mathrm{TiO}_{2}$ with different calcinations temperature which were calculated by Scherrer equation ${ }^{56}$. It is well known that particle sizes play a vital role in photocatalytic activity since smaller crystals offer greater surface area to volume ratios and thus induce better surface absorbability of hydroxyl/water, which in-turn acts as an active oxidizer in the photocatalytic reaction. In addition, the increase of nominal 
nitrogen content and increase the calcination temperature leads to an increase of the average crystal size of $\mathrm{N}$-doped $\mathrm{TiO}_{2}$. It can therefore be concluded that the level of nitrogen doping has a significant effect on the particle size of $\mathrm{TiO}_{2}$ grown during the doping process.

Table 1. Crystalline size and phase composition of $N$-doped $\mathrm{TiO}_{2}$ (NT) with different calcination temperature

\begin{tabular}{ccc}
\hline $\begin{array}{c}\text { NT at difference calcinations } \\
\text { temperature, }{ }^{0} \mathrm{C}\end{array}$ & $\begin{array}{c}\text { Phase } \\
\text { Composition }\end{array}$ & $\begin{array}{c}\text { Average Crystalline } \\
\text { Size/nm }\end{array}$ \\
\hline 400 & Anatase & 19 \\
600 & Anatase & 28 \\
800 & Anatase, Rutile & 52 \\
\hline
\end{tabular}

EDAX analysis

EDAX patterns of $\mathrm{N}-\mathrm{TiO}_{2}$ indicated Titanium and Oxygen as the major elements in the photocatalyst. The Figure 6 confirms the presence of dopant nitrogen in $\mathrm{TiO}_{2}$.

\section{Conclusion}

This study examined the preparation, characterization and photocatalytic study of Nitrogen doped titania photocatalyst. $\mathrm{TiO}_{2}$ nanoparticles were prepared by sol-gel method. From the SEM-EDX, UV-Vis results, it was confirmed that the incorporation of $\mathrm{N}$ in $\mathrm{TiO}_{2}$ decreases the grain size and hence increases the photocatalytic degradation of Rhodamine $\mathrm{B}$ dye under visible light irradiation. Overall, Nitrogen doped $\mathrm{TiO}_{2}$ photocatalysts revealed it's potential for rapid degradation of $\mathrm{RB}$ dye in wastewater using visible light. $\mathrm{N}$ doped $\mathrm{TiO}_{2}$ possesses the highest visible light absorption and the best photocatalytic activity.

\section{References}

1. Zolinger H, (Ed.), Color chemistry: Synthesis, Properties and applications of Organic Dyes and Pigments, VCH, 1991.

2. Prado A G S, Bol Zon L B, PedrosoC P, Moura AO and CostaL L, Appl Catal B: Environ., 2008, 82(3-4), 219-224; DOI:10.1016/j.apcatb.2008.01.024

3. Litter M I. Appl Catal B: Environ., 1999, 23(2-3), 89-114; DOI:10.1016/S09263373(99)00069-7

4. $\quad$ Yu J C, Lin J, Lo D and Lam S K, Langmuir, 2000, 16(18), 7304-7308; DOI:10.1021/la000309w

5. Fujishima A, Rao T N and Tryk D A, J Photochem Photobiol C: Photochem Rev., 2000, 1, 1-21; DOI:10.1016/S1389-5567(00)00002-2

6. Fox M A and Dulay M T, Chem Rev., 1993, 93(1), 341-357;

DOI:10.1021/cr00017a016

7. Mills A and Hunte S L, J Photochem Photobiol A, 1997, 108, 1-35;

DOI:10.1016/S1010-6030(97)00118-4

8. Yamashita H, lachihashi Y, Takeuchi M, Kishiguchi S and Anpo M, J Synchrotron Radiat., 1999, 6(3), 451-452; DOI:10.1107/S0909049598017257

9]. Klosek S and Raftery D, J Phys Chem B, 2001, 105(14), 2815-2819; DOI:10.1021/jp004295e

10. Anpo M and Takeuchi M, J Catal., 2003, 216(1-2), 505-516; DOI:10.1016/S00219517(02)00104-5

11. Ghosh A K and Maruska H P, J Electrochem Soc., 1977, 124(10), 1516-1522; DOI:10.1149/1.2133104 
12. Choi W Y, Termin A and Hoffmann M R, J Phys Chem., 1994, 98(51), 13669-13679; DOI:10.1021/j100102a038

13. Wang Y Q, Zhang L, Cheng H M and Ma J M, Chem J Chinese U, 2000, 21, 958-960.

14. Sakthivel S, Janczarek M and Kisch H, J Phys Chem B, 2004, 108(50), 19384-19387; DOI:10.1021/jp046857q

15. Asashi R, Morikawa T, Ohwaki T, Aoki K and Taga Y, Science, 2001, 293(5528), 269-271.

16. Mokawa T, Asahi R, Ohwaki T, Aoki K and Taga Y, Jpn J Appl Phys., 2001, 40, 561-563.

17. Irie H, Watanabe $\mathrm{Y}$ and Hashimoto K, J Phys Chem B, 2003, 107(23), 5483-5486; DOI:10.1021/jp030133h

18. Burda C, Lou Y B, Chen X B and Samia A C, Stout J and Gole J L, Nano Lett., 2003, 3(8), 1049-1051; DOI:10.1021/n1034332o

19. Diwald O, Thompson T L, Zubkov T, Goralski E G, Walck S D and Yates J T, J Phys Chem B, 2004, 108(19), 6004-6008; DOI:10.1021/jp031267y

20. Khan S U M, Alshahry M and Ingler Jr W B, Science, 2002, 297(5590), 2243-2244.

21. Irie H, Watanabe $\mathrm{Y}$ and Hashimoto K, Chem Lett., 2003, 32(8), 772-773; DOI:10.1246/cl.2003.772

22. Sakthivel S and Kisch H, Angew Chem Int Ed., 2003, 42(40), 4908-4911; DOI:10.1002/anie.200351577

23. Choi Y, Umebayshi Y and Yoshikawa M, J Mater Sci., 2004, 39(5), 1837-1839; http://dx.doi.org/10.1023/B:JMSC.0000016198.73153.31

24. Umebayashi T, Yamaki T, Itoh H and Asai K, Appl Phys Lett., 2002, 81(3), 454-456; DOI:10.1063/1.1493647

25. Umebayashi T, Yamaki T, Tamaka S and Asai K Chem Lett., 2003, 32(4), 330-331; DOI:10.1246/cl.2003.330

26. Ohno $\mathrm{T}$, Mitsui $\mathrm{T}$ and Matsumura M, Chem Lett., 2003, 32(4), 364-365; DOI:10.1246/cl.2003.364

27. Hong X T, Wang Z P, Cai W M, Lu F, Zhang J, Yang Y Z, Ma N and Liu Y J, Chem Mater., 2005, 17(6), 1548-1552; DOI:10.1021/cm047891k

28. Watanabe T, Takizawa T and Honda H, J Phys Chem., 1977, 81(19), 1845-1851; DOI:10.1021/j100534a012

29. Takizawa T, Watanabe T and Honda K, J Phys Chem., 1978, 82(12), 1391-1396; DOI:10.1021/j100501a014

30. P.Qu.J.Zhao,T.Shen,H.Hidaka, J Mol Catal A: Chem., 1998, 129(2-3), 257-268; DOI:10.1016/S1381-1169(97)00185-4

31. Song W, Xiaohong W, Wei Q and Zhaohua J, Electrochim Acta, 2007, 53(4), 18831889; DOI:10.1016/j.electacta.2007.08.039

32. Wu X H, Jiang Z H, Liu H L, Li X D and Hu X G, Mater Chem Phys., 2003, 80(1), 39-43; DOI:10.1016/S0254-0584(02)00512-6

33. Karuppuchamy S, Suzuki N, Ito S and Endo T,Curr Appl Phys., 2009, 9(1), 243-248; DOI:10.1016/j.cap.2008.02.004

34. Fan L, Ichikuni N, Shimazu S and Uematsu T, Appl Catal A: Gen., 2003, 246(1), 87-95; DOI:10.1016/S0926-860X(03)00002-4

35. Chen J, Zhang J, Xian Y, Ying X, Liu M and Jin L, Water Res., 2005, 39(7), 13401346; DOI:10.1016/j.watres.2004.12.045

36. Takahashi M, Tsukigi K, Uchino T and Yoko T, Thin Solid Films, 2001, 388(1-2), 231-236; DOI:10.1016/S0040-6090(01)00811-2 
37. Patil K R, Sathaye S D, Khollam Y B, Deshpande S B, Pawaskar N R and Mandale A B, Mater Lett., 2003, 57(12), 1775-1780; DOI:10.1016/S0167-577X(02)01067-4

38. Cheng F, Peng Z, Liao C, Xu Z, Gao S, Yan C, Wang D and Wang J, Solid State Commun., 1998, 107(9), 471-476; DOI:10.1016/S0038-1098(98)00265-8

39. Prasad S, Vijayalakshmi A and Gajbhiye N S, Therm Anal Calorim., 1998, 52(2), 595-607.

40. Dvoranova D, Brezova V, Mazur M and Malati M A, Appl Catal B: Environ., 2000, 37(2), 91-105; DOI:10.1016/S0926-3373(01)00335-6

41. Lee A C, Lin R H, Yang C Y, Lin M H and Wang W Y, Mater Chem Phys., 2007, 109(2-3), 275-280; DOI:10.1016/j.matchemphys.2007.11.016

42. Li Y and Demopoulos G P, Hydrometallurgy, 2008, 90(1), 26-33; DOI:10.1016/j.hydromet.2007.09.008

43. Sun J, Qiao L, Sun S and Wang G, J Hazard Mater., 2008, 155(1-2), 312-319; DOI:10.1016/j.jhazmat.2007.11.062

44. Ohno T, Akiyoshi M, Umebayashi T, Asai K, Mitsui T and Matsumura M, Appl Catal A: Gen., 2004, 265(1), 115-121; DOI:10.1016/j.apcata.2004.01.007

45. Zhu J, Deng Z, Chen F, Zhang J, Chen H, Anpo M, Huang J and Zhang L, Appl Catal B: Environ., 2006, 62(3-4), 329-335; DOI:10.1016/j.apcatb.2005.08.013

46. Zhiyu W, Haifeng C, Peisong T and Weiping M, Fuan Z, Guodong Q and Xianping F, Colloids Surf A: Physicochem Eng Aspects, 2006, 289(1-3), 207-211; DOI:10.1016/j.colsurfa.2006.04.049

47. Wang F, Shi Z, Gong F, Jiu J and Adachi M, Chin J Chem Eng., 2007, 15(5), 754-759; DOI:10.1016/S1004-9541(07)60158-X

48. Peng F, Cai L, Huang L, Yu H and Wang H, J Phys Chem Solids, 2008, 69(7), 16571664; DOI:10.1016/j.jpcs.2007.12.003

49. Zhao X, Liu M and Zhu Y, Thin Solid Films, 2007, 515(18), 7127-7134; DOI:10.1016/j.tsf.2007.03.025

50. Li G, Chen L, Dimitrijevic N M and Gray K A, Chem Phys Lett., 2008, 451(1-3), 75-79; DOI:10.1016/j.cplett.2007.11.071

51. Babelon P, Dequiedt A S, Mostefa-Sba H, Bourgeois S, Sibillot P and Sacilotti M, Thin Solid Films, 1998, 322(1-2), 63-67; DOI:10.1016/S0040-6090(97)00958-9

52. Kim B H, Lee J Y, Choa Y H, Higuchi M and Mizutani N, Mater Sci Eng., 2004, B107(3), 289-294; DOI:10.1016/j.mseb.2003.12.010

53. Ghorai T K, Dhak D, Biswas S K, Dalai S and Pramanik P, J Mol Catal A: Chem., 2007, 273(1-2), 224-229; DOI:10.1016/j.molcata.2007.03.075

54. Zhang X, Zhou M and Lei L, Appl Catal A: Gen., 2005, 282(1-2), 285-293; DOI:10.1016/j.apcata.2004.12.022

55. Zhang X and Lei L, Mater Lett., 2008, 62(6-7), 895-897;

DOI:10.1016/j.matlet.2007.07.007

56. Saravanan P, Pakshirajan K and Saha P, J Hydro- Environ Res., 2009, 3(1), 45-50; DOI:10.1016/j.jher.2009.04.001 